\title{
Calculations of hyperfine coupling constant of the TMPD molecule
}

\author{
Michal Malček, Lukáš Bučinský, Stanislav Biskupič \\ Department of Physical Chemistry, Faculty of Chemical and Food Technology, \\ Slovak University of Technology in Bratislava, Radlinského 9, SK-812 37 Bratislava, Slovak Republic \\ michal.malcek@stuba.sk
}

\begin{abstract}
The calculations of the hyperfine coupling constants (HFCC) of tetramethyl-p-Phenylenediamine (TMPD) are presented. Several DFT functionals are employed and the results are compared with the UHF and MP2 level of theory. Sensitivity of HFCC to the choice of the basis set is investigated. Impact of the different conformers of TMPD and the equivalence of methyl group hydrogens on the HFCC values is considered. The solvent effects are introduced via polarizable continuum model and compared with in vacuo calculations. Last but not least, molecular dynamics is employed to include the solvent molecules as well as the dynamics explicitly, accounting similar conditions comparing to the liquid phase EPR experiment.
\end{abstract}

Keywords: electron correlation, hyperfine coupling constant, molecular dynamics, p-Phenylenediamine, solvent effect

\section{Introduction}

The most important feature of the EPR spectra is their hyperfine structure. The source of this phenomenon is the magnetic interaction between the spin of an unpaired electron with the magnetic moments of nuclei in a radical. From theoretical point of view the splitting of the signal in the liquid phase EPR experiment can be obtained by means of the isotropic Fermi hyperfine coupling constant (HFCC), which is a good approximation for organic radicals. The isotropic hyperfine Fermi coupling constant reads:

$A_{F}=-\frac{8}{3} \pi \beta_{e} \beta_{N} g_{N} g_{e} \frac{1}{S_{Z}}\left\langle\Psi_{0}\left|\hat{S}_{Z} \delta(r)\right| \Psi_{0}\right\rangle$

where: $g_{N}-\mathrm{g}$-factor of the nucleus, $g_{e}-\mathrm{g}$-factor of the electron, $\beta_{e}-$ Bohr magneton, $\beta_{N}-$ nuclear magneton, $S_{Z}$ - operator of spin momentum and $\left\langle\Psi_{0}\left|\hat{S}_{z} \delta(r)\right| \Psi_{0}\right\rangle$ - eigenvalue of the spin density at the nucleus.

The molecule studied in this paper is the tetramethyl-p-Phenylenediamine radical (TMPD) (see Fig 1), also known as Wûrster's blue (Grampp et al. 2005). This compound belongs to the group of colored organic radicals based on the p-Phenylenediamine, which are known as Würster's cations (discovered by German chemist Casimir Wûrster more than 100 years ago). These compounds are used in a wide range of industrial applications, mainly as coupling components in the developing process of color films and thin foils.

The quite simple molecule of TMPD can actually have several configurations, according to the orientation of the methyl groups in the space (see Fig. 2).<smiles>CN(C)c1ccc(N(C)C)cc1</smiles>

Fig. 1. Tetramethyl-p-Phenylenediamine radical (TMPD).

Statistical population $n_{i} / N$ (molar fraction) of one of the configurations is given by its energy according to the Boltzmann distribution

$$
\frac{n_{i}}{N}=\frac{\exp \left(-\beta \varepsilon_{i}\right)}{\sum_{j} \exp \left(-\beta \varepsilon_{j}\right)}
$$

where $\beta=1 / \mathrm{kT}$ ( $\mathrm{k}$ is the Boltzman constant and $\mathrm{T}=293.15 \mathrm{~K}), \varepsilon_{\mathrm{i}}$ is the SCF energy of the $\mathrm{i}$-th conformer relative to the conformer with the lowest energy and

$$
N=\sum_{j} n_{j} .
$$

The final value of hyperfine coupling constant $A_{F}$ then reads:

$$
A_{F}=\sum_{i} A_{F, i} n_{i} / N
$$

Furthermore, the hydrogens of the methyl group are in the EPR experiment in liquid phase equiva- 


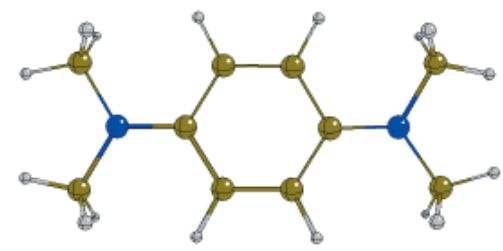

a) $4 \mathrm{a}$

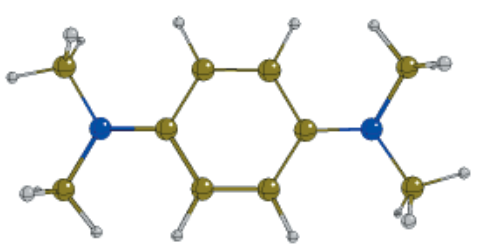

d) 2a2b-trans

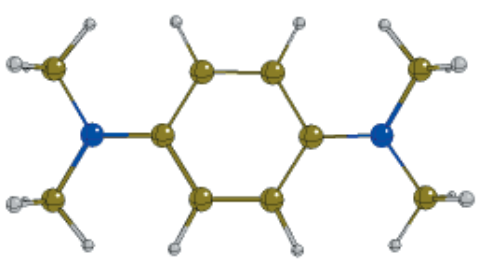

b) $4 \mathrm{~b}$

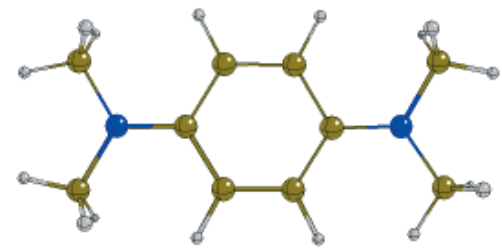

e) $3 \mathrm{a} 1 \mathrm{~b}$

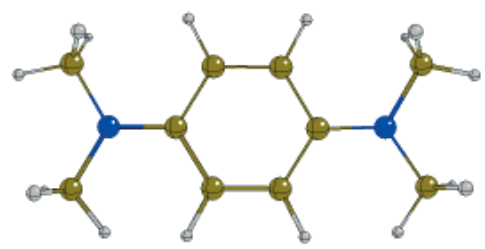

c) $2 \mathrm{a} 2 \mathrm{~b}-\mathrm{cis}$

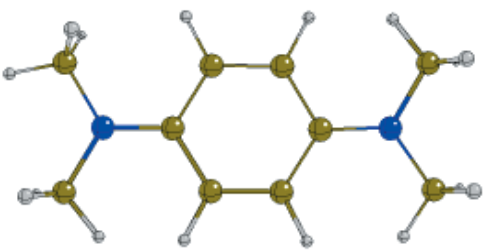

f) $1 \mathrm{a} 3 \mathrm{~b}$

Fig. 2. Conformers of TMPD and their labels.

lent because of the free rotation of this group. But, in quantum chemistry the skeleton of a molecule is fixed, in which case these hydrogens are not equivalent anymore. In the TMPD radical one of the hydrogens of each of the $\mathrm{CH}_{3}$ group is in the plane of the benzene ring and the other two are placed above and below the plane. Hence, instead of one HFCG value for all the methyl group hydrogens, one obtains three different (one related to the planar hydrogen and two very similar related to the non-planar hydrogens) values of HFCC. Nonetheless, there are several ways to face this issue of making the hydrogens again equivalent.

The first option is a simple arithmetic mean of all the values of HFCC related to the hydrogens of methyl groups in a given molecule (see Table 2 ). This is the most elementary approach which is very often employed and does not demand any additional calculations.

The second option is to simulate the rotation of one of the methyl groups. This method has been performed by using a set of geometries of the TMPD radical with one of the methyl groups rotated between $0-60^{\circ}\left(e . g\right.$. with a step of $\left.5^{\circ}\right)$. The rest of the molecule has been fixed (the geometry has not been relaxed/optimized during the rotation of the methyl group). The final value of HFCC can be obtained in two different ways, one is the arithmetic mean of all the HFCG values of the hydrogens of the rotated geometries (this is equal to a free rotation). The second one accounts the dependence of the relative energy on the dihedral angle and makes use of equations 2 and 3 to obtain the final HFCC constant of a statistically weighted rotation of the methyl group.

Last but not least, one can employ molecular dynamics (Alder and Wainwright 1957). In such a case one can include explicitly the solvent molecules and the simulation of the motion of the molecule (rotation of the methyl group and vibrations as well) within the calculation of a given property (Rimarčík et al. 2010).

The main goals of this work are the calculations of HFCG by using modern methods of computational chemistry. The work is focused on the sensitivity of HFCG to different kinds of correlation effects such as electron correlation, molecular dynamics, effect of the solvent (comparison of the continuum model with an explicit treatment of the solvent), influence of the basis set quality, conformational analysis and the issue of the equivalence of hydrogens of the methyl groups.

\section{Computational details}

Calculations in the Gaussian03 package (Frisch et al. 2003) were performed at the UHF, at the DFT level of theory (Parr and Young 1989) and at the second order Móller - Plesset perturbation level of theory (MP2) (Moller and Plesset 1934). Besides the B3LYP functional (Kim and Jordan 1994, Stephens et al. 1994), the PBE (Perdew et al. 1996), BLYP (Becke 1988), PBE0 (Adamo and Barone 1999) and M06 (Zhao and Truhlar 2006) functionals have been tested. Calculations using the M06 functionals were performed in the NWChem package (Bylaska et al. 2010). The following basis sets have been used in the presented calculations: cc-pVDZ, aug-cc-pVDZ, uncontracted aug-cc-pVDZ (denoted as UDZ), cc-pVTZ, cc-pVQZ (Dunning 1989), 3-21G (Binkley et al. 1980), 6-31G, 6-31G* (Hehre et al. 1972), 6-311G** (Krishnan et al. 1980) and the eprII / eprIII basis sets which were developed for the calculations of EPR parameters (Barone 1996). The sensitivity of HFCC to solvation models 
was investigated by means of polarized continuum models of Gaussian03 package; PCM, CPCM (Miertus et al. 1981, Barone and Cossi 1998). The solvation models have been tested with the cc-pVDZ basis set. Acetonitrile and methanol have been used as solvents. The geometry of TMPD was optimized for the given level of theory, basis set and environment (PGM, CPGM or in vacuo).

The MD calculations were performed in the NWChem package (Bylaska et al. 2010), using the M06 DFT functional (Zhao and Truhlar 2006) and the 3-21G basis set (Binkley et al. 1980). The Berendsen thermostat was set to $298 \mathrm{~K}$, time step was $0.1 \mathrm{fs}$, and the simulation was 1000 steps long. Velocity has been reassigned every 250 time-steps. The relaxation was set to 250 time steps as well. Values of HFCG were calculated in the NWChem package (using B3LYP method and cc-pVDZ basis set) from fifty (twenty five) geometries/frames of the MD simulation, beginning with step number 499 (749) for each 10th step. The final HFCG value has been obtained as the arithmetic mean from all the fifty (twenty five) MD geometries.

\section{Results and discussions}

\section{Conformers of TMPD}

The TMPD molecule contains four methyl groups - two on each nitrogen in the para positions of the benzene ring. The possible six different conformations of the TMPD molecule which are defined by the orientation of the methyl groups are shown in Fig 2. Nonetheless, a given conformer can have a different number of equal geometries by means of the labels of the methyl groups, see the count of combinations (multiplicity) in Table 1.

Energies of all possible conformers were obtained using the B3LYP functional in the aug-cc-pVDZ basis set, with and without inclusion of the PCM solvent model (see Table 1). Nonetheless, geometry of conformer $4 \mathrm{a}$ has been optimized at the B3LYP/ aug-cc-pVDZ level, while the remaining conformers have been obtained as single points of the rotated methyl groups of the 4a geometry, see the discussion below. Relative energies and average values of HFCG for all conformers are presented in Table 1. The HFCG values obtained by means of Boltzmann statistics are presented in parenthesis of Table 1.

One can see from Table 1 that conformer $4 \mathrm{a}$ is the most stable (statistical abundance over $96 \%$ assuming $293.15 \mathrm{~K}$ ), while conformer $4 \mathrm{~b}$ is the least stable. It is caused because of the repulsion between the hydrogen of the methyl group and the hydrogen on the benzene ring.

As is shown in Table 1, the most sensitive to the change of conformation are the HFCC constants of the hydrogens of the methyl groups. It is clearly to see that the averaged values of HFCG for the methyl group hydrogens obtained by Boltzmann statistics is in a better agreement with the experimental data

Tab. 1. In vacuo and PCM(ACN) calculations at the B3LYP/aug-cc-pVDZ level of TMPD conformers, relative energy, number of equal combinations, the fraction and HFCC for nitrogen, hydrogens on aromatic ring and methyl group hydrogens.

\begin{tabular}{|c|c|c|c|c|c|c|}
\hline conformation & $\begin{array}{c}\text { count of } \\
\text { combinations }\end{array}$ & $\begin{array}{l}\text { rel. energy } \\
\text { a.u. }\end{array}$ & $n_{i} / N$ & $\begin{array}{l}\mathrm{A}_{\mathrm{F}}(\mathrm{N}) \\
\text { Gauss }\end{array}$ & $\begin{array}{c}\mathrm{A}_{\mathrm{F}}\left(\mathrm{H}_{\text {arom }}\right) \\
\text { Gauss }\end{array}$ & $\begin{array}{c}\mathrm{A}_{\mathrm{F}}\left(\mathrm{H}_{\text {metyl }}\right) \\
\text { Gauss }\end{array}$ \\
\hline \multicolumn{7}{|c|}{ in vacuo } \\
\hline $4 a$ & 1 & 0 & 0.9559 & 7.912 & -1.718 & 6.645 \\
\hline $4 b$ & 1 & 0.016052 & 0.0000 & 8.053 & -1.722 & 5.935 \\
\hline $1 \mathrm{~b} 3 \mathrm{a}$ & 4 & 0.004163 & 0.0430 & 7.938 & -1.714 & 6.453 \\
\hline $2 \mathrm{a} 2 \mathrm{~b}$ cis & 2 & 0.007757 & 0.0004 & 7.993 & -1.719 & 6.279 \\
\hline 2a2b trans & 2 & 0.007413 & 0.0006 & 8.012 & -1.718 & 6.271 \\
\hline $1 \mathrm{a} 3 \mathrm{~b}$ & 4 & 0.011737 & 0.0000 & 8.028 & $-1,721$ & 6.103 \\
\hline average & & & & $\begin{array}{c}7.989 \\
(7.912)^{\mathrm{a}} \\
\end{array}$ & $\begin{array}{c}-1.719 \\
(-1.718)^{a} \\
\end{array}$ & $\begin{array}{c}6.281 \\
(6.636)^{\mathrm{a}}\end{array}$ \\
\hline \multicolumn{7}{|c|}{ pcm model } \\
\hline $4 a$ & 1 & 0 & 0.9575 & 7.826 & -1.723 & 6.615 \\
\hline $4 b$ & 1 & 0.015359 & 0.0000 & 7.961 & -1.724 & 5.803 \\
\hline $1 b 3 a$ & 4 & 0.004204 & 0.0412 & 7.862 & -1.717 & 6.347 \\
\hline $2 \mathrm{a} 2 \mathrm{~b}$ cis & 2 & 0.007638 & 0.0005 & 7.914 & -1.721 & 6.165 \\
\hline 2a $2 \mathrm{~b}$ trans & 2 & 0.007244 & 0.0008 & 7.934 & -1.720 & 6.158 \\
\hline $1 \mathrm{a} 3 \mathrm{~b}$ & 4 & 0.011346 & 0.0000 & 7.943 & -1.722 & 5.981 \\
\hline average & & & & $\begin{array}{c}7.908 \\
(7.828)^{\mathrm{a}}\end{array}$ & $\begin{array}{c}-1.720 \\
(-1.723)^{\mathrm{a}}\end{array}$ & $\begin{array}{c}6.179 \\
(6.603)^{\mathrm{a}}\end{array}$ \\
\hline EXP (Gra & pp 2005) & & & 7.051 & 1.989 & 6.770 \\
\hline
\end{tabular}

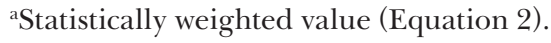


than the values gained by a simple arithmetic mean. It is obvious, because the abundance of conformer $4 \mathrm{a}$ is $96 \%$. The abundance of conformer $1 \mathrm{~b} 3 \mathrm{a}$ is $4 \%$ and the contribution of the remaining conformers is actually negligible. Differences between HFCG calculated with and without the inclusion of the solvent model are not very significant. The solvent effects will be more closely discussed in one of the coming subchapters (see also Table 2).

Nonetheless, one further important point is that besides conformer $4 \mathrm{a}$ all remaining conformers are transition states for the different rotations of the methyl groups. Hence, the above discussion is related to the sensitivity of HFCCs to conformational changes in general and the impact on HFCC in the case of TMPD is rather limited. Nonetheless, in the case of systems with several stable conformers the impact of conformations and the inclusion of Boltzmann statistics might be important.

\section{The influence of the level of theory}

(UHF vs. DFT vs. MP2) on the HFCC

The average $\mathrm{HFCC}$ values of nitrogen $\mathrm{A}_{\mathrm{F}}(\mathrm{N})$, hydrogens on the aromatic ring $\mathrm{A}_{\mathrm{F}}\left(\mathrm{H}_{\text {arom }}\right)$ and the methyl

Tab. 2. Table of HFCG in Gauss for different basis sets and solvation models.

\begin{tabular}{|c|c|c|c|c|c|}
\hline Method & Basis set & Solvation model & $\mathrm{A}_{\mathrm{F}}(\mathrm{N})$ & $\mathrm{A}_{\mathrm{F}}\left(\mathrm{H}_{\mathrm{arom}}\right)$ & $\mathrm{A}_{\mathrm{F}}\left(\mathrm{H}_{\mathrm{CH}_{3}}\right)$ \\
\hline \multirow[t]{7}{*}{ UHF } & cc-pVDZ & $\operatorname{PCM}(\mathrm{ACN})$ & 16.660 & -2.302 & 6.476 \\
\hline & & in vacuo & 16.994 & -2.311 & 6.548 \\
\hline & aug-cc-pVDZ & in vacuo & 17.804 & -2.317 & 6.455 \\
\hline & UDZ & in vacuo & 15.069 & -2.141 & 6.322 \\
\hline & cc-pVTZ & in vacuo & 11.469 & -2.283 & 6.784 \\
\hline & $6-31 G$ & in vacuo & 18.934 & -2.681 & 8.151 \\
\hline & $3-21 \mathrm{G}$ & in vacuo & 17.412 & -2.302 & 6.848 \\
\hline \multirow[t]{19}{*}{ B3LYP } & cc-pVDZ & $\operatorname{PCM}(\mathrm{ACN})$ & 7.608 & -1.709 & 6.717 \\
\hline & & PCM(MeOH) & 7.608 & -1.708 & 6.724 \\
\hline & & CPCM(ACN) & 7.608 & -1.709 & 6.717 \\
\hline & & $\mathrm{CPCM}(\mathrm{MeOH})$ & 7.607 & 1.708 & 6.720 \\
\hline & & in vacuo & 7.679 & -1.708 & 6.737 \\
\hline & aug-cc-pVDZ & $\operatorname{PCM}(\mathrm{ACN})$ & 7.826 & -1.723 & 6.615 \\
\hline & & PCM(MeOH) & 7.827 & -1.722 & 6.616 \\
\hline & & in vacuo & 7.912 & -1.718 & 6.645 \\
\hline & UDZ & $\operatorname{PCM}(\mathrm{ACN})$ & 5.317 & -1.585 & 6.681 \\
\hline & & $\operatorname{PCM}(\mathrm{MeOH})$ & 5.315 & -1.585 & 6.677 \\
\hline & & in vacuo & 5.374 & -1.578 & 6.701 \\
\hline & cc-pVTZ & in vacuo & 3.323 & -1.670 & 7.202 \\
\hline & cc-pVQZ & in vacuo & 4.089 & -1.734 & 7.510 \\
\hline & $3-21 G$ & in vacuo & 7.677 & -1.648 & 6.370 \\
\hline & $6-31 \mathrm{G}$ & in vacuo & 8.442 & -1.967 & 7.705 \\
\hline & $6-31 G^{*}$ & in vacuo & 7.476 & -1.896 & 7.313 \\
\hline & $6-311 \mathrm{G} * *$ & in vacuo & 4.718 & -1.724 & 7.073 \\
\hline & epr-II & in vacuo & 5.532 & -1.857 & 7.758 \\
\hline & epr-III & in vacuo & 5.488 & -1.818 & 7.856 \\
\hline BLYP & cc-pVDZ & in vacuo & 6.296 & -1.667 & 6.940 \\
\hline PBE & cc-pVDZ & in vacuo & 6.028 & -1.746 & 7.230 \\
\hline PBE0 & cc-pVDZ & in vacuo & 8.033 & -1.848 & 7.038 \\
\hline $\mathrm{M} 06^{\mathrm{a}}$ & cc-pVDZ & in vacuo & 7.021 & -2.319 & 6.807 \\
\hline B3LYPa & cc-pVDZ & in vacuo & 6.242 & -1.705 & 6.736 \\
\hline \multirow[t]{9}{*}{ MP2 } & cc-pVDZ & $\mathrm{PCM}(\mathrm{ACN})$ & 6.962 & -2.677 & 5.832 \\
\hline & & in vacuo & 6.683 & -2.661 & 5.734 \\
\hline & aug-cc-pVDZ & in vacuo & 6.369 & -2.620 & 5.452 \\
\hline & UDZ & in vacuo & 2.468 & -2.395 & 5.369 \\
\hline & cc-pVTZ & in vacuo & -0.051 & -2.531 & 5.764 \\
\hline & $3-21 G$ & in vacuo & 8.543 & -2.687 & 5.469 \\
\hline & $6-31 G$ & in vacuo & 9.198 & -3.277 & 6.683 \\
\hline & epr-II & in vacuo & 3.189 & -2.833 & 6.299 \\
\hline & epr-III & in vacuo & 1.848 & -2.697 & 6.256 \\
\hline \multicolumn{2}{|c|}{ EXP (Grampp et al. 2005) } & & 7.051 & 1.989 & 6.770 \\
\hline B3LYP & $6-31 \mathrm{G}^{*}$ & & 6.520 & 1.900 & 7.310 \\
\hline (Grampp 2005) & epr-II & & 5.520 & 1.850 & 7.810 \\
\hline
\end{tabular}

${ }^{a}$ Results obtained from NWChem package. 
group hydrogens $\mathrm{A}_{\mathrm{F}}\left(\mathrm{H}_{\mathrm{CH} 3}\right)$ of TMPD (conformer $4 \mathrm{a}$ ) at different levels of theory are presented in Table 2. The sensitivity of HFCG to basis set quality and solvation models is presented in Table 2 as well.

The UHF method gives an acceptable agreement with experiment (by means of HFCC) only for the methyl group hydrogens. In the case of $\mathrm{A}_{\mathrm{F}}(\mathrm{N}), \mathrm{UHF}$ completely fails. HFCG values for this nitrogen are highly overestimated (nearly 2.5 times bigger relative to the experiment), see Table 2 . This should be assigned to the missing electron correlation at the UHF level. A lower value of $A_{F}(N)$, in comparison with the DZ-like or 3-21g basis sets, was obtained in the cc-pVTZ basis set, but it is still overestimated (60\%) relative to the experimental value. Values of HFCG for hydrogens on the benzene ring $\mathrm{A}\left(\mathrm{H}_{\mathrm{CH} 3}\right)$ are in closer agreement to experiment than those obtained at MP2 level of theory, but still worse than in the case of B3LYP or other DFT functionals.

B3LYP gives almost quantitative agreement with the obtained experimental HFCG values for hydrogens. In the case of cc-pVDZ, aug-cc-pVDZ and UDZ values of $\mathrm{A}_{\mathrm{F}}\left(\mathrm{H}_{\mathrm{CH} 3}\right)$ the agreement with experiment was excellent (differences between computed and experimental value were just about $1-2 \%)$. In the case of $\mathrm{A}_{\mathrm{F}}\left(\mathrm{H}_{\text {arom }}\right)$ the agreement for the DZ quality basis sets is rather quantitative and the best result was obtained with the $6-31 \mathrm{~g}$ basis set. In the case of B3LYP $A_{F}(N)$ values the difference between experiment and theory is still acceptable (around $8 \%$ in the case of cc-pVDZ basis set). In the case of other DFT functionals using the ccpVDZ basis set, the best results were obtained with M06 functional in NWChem package (the reason for testing this functional is the later usage in the MD calculations). Non-hybrid functionals (BLYP and PBE) significantly underestimate the values of $A_{F}(N)$ and $A_{F}\left(H_{\text {arom }}\right)$, though the values are still acceptable. Interesting is also the large difference between $A_{F}(N)$ values obtained by the different versions of B3LYP functional in the NWChem and the Gaussian03 packages, respectively.

The MP2 method seems not to be suited for the evaluation of HFCC. The HFCCs obtained at the MP2 level are strongly dependent on the basis set choice (especially in the case of nitrogen). In the case of HFCC for the aromatic hydrogens, MP2 yields similar accuracy in comparison with experiment like the UHF method. The $\mathrm{A}_{\mathrm{F}}\left(\mathrm{H}_{\mathrm{CH} 3}\right)$ values at the MP2 level of theory seem to be in average underestimated relative to the experiment. The exception is only 6-31g basis set. In general, results obtained by MP2 method were not in better agreement to experimental values than the one obtained by B3LYP, in addition MP2 is computationally much more demanding than B3LYP.
Considering all the facts, B3LYP functional is an appropriate method for the calculations of HFCC, although all the tested DFT functionals yielded considerable agreement with experimental data. In the following calculations related to the issue of the equivalence of methyl group hydrogens, conformations, molecular dynamics the UHF and MP2 methods were not accounted.

\section{Sensitivity of the HFCC to solvation via continuum solvent models}

One can see from Table 2 that the influence of the solvation model is not very significant in calculations of HFCG of TMPD. Solvation has a small impact on $A_{F}(N)$ and in the case of hydrogens it is negligible. In the case of the TMPD molecule there is no difference between the HFCG values obtained by PCM and CPCM models (B3LYP/cc-pVDZ level of theory). In addition, B3LYP HFCC are not sensitive to the choice of a solvent, see the values for ACN and $\mathrm{MeOH}$ in Table 2. Nonetheless, the impact of solvation for the $\mathrm{NO}_{2}$ containing radicals, for instance, has been found much more significant and considerably improves the agreement with experiment (Rimarčík et al. 2011, Brezová et al. unpublished).

\section{Sensitivity of the HFCC to the choice of the basis set}

Besides the importance of the choice of a method for HFCC calculations, the basis set choice is a non trivial task as well. Surprisingly, basis sets of DZ (or even lower quality) yield a considerably better agreement between experimental and theoretical HFCG values than the TZ/QZ quality basis sets (these values are significantly underestimated especially in the case of $A_{F}(N)$ ). The cc-pVQZ basis set gave a slightly better agreement in the case of the $A_{F}(N)$ and $A_{F}\left(H_{\text {arom }}\right)$ in comparison to cc-pVTZ. However $\mathrm{A}_{\mathrm{F}}\left(\mathrm{H}_{\mathrm{CH} 3}\right)$ obtained with cc-pVQZ is the worst among the B3LYP HFCGs of the methyl group.

The low quality 3-21 g basis set yielded quantitatively a surprisingly good agreement with the experimentally obtained HFCG values. The $6-31 \mathrm{~g}$ basis set yielded a worse agreement with experiment than $3-21 \mathrm{~g}$ basis set. Pople style TZ basis set 6-311g** (Hehre et al. 1972) did not improve the agreement with experiment as well (especially in the case of $A_{F}(N)$, which was too far from experiment). Only the 6-31g* B3LYP HFCG values are in a good correlation with experiment.

Basis sets developed especially for calculations of EPR parameters at the DFT level of theory epr-II and epr-III did not bring the expected agreement with experiment, only $\mathrm{A}_{\mathrm{F}}\left(\mathrm{H}_{\text {arom }}\right)$ are close to the experimental results (see Table 2 ). 
Impact of rotation of the methyl group on HFCC Calculations of HFCG with the inclusion of the rotation of the methyl group were performed in vacuo, using the B3LYP method and aug-cc-pVDZ and/or UDZ basis sets. In these calculations only the dihedral angle of the methyl group was changed and the rest of the molecule was fixed. Step size of the rotation of the dihedral angle was $5^{\circ}$.

Dependence of the B3LYP energies (relative to the conformer 4a) and of the HFCCs of the hydrogens of the rotating $\mathrm{CH}_{3}$ group upon the dihedral angle are shown in Figs. 3, for both aug-cc-pVDZ and UDZ basis sets.

In Table 3, are shown the final HFGC values for TMPD. Values in the first column were obtained by simple arithmetic mean of all the three hydrogens of the rotated methyl group (see Table 2), values in the second column are from conformational analysis (see Table 1), values in the third column were obtained by considering the free rotation of the methyl group (see Fig. 3 ) and values in the forth column are based on the weights from Boltzmann statistics (Equation 1). One can see that all numbers in Table 3 give a good agreement with experimental value of $\mathrm{A}_{\mathrm{F}}\left(\mathrm{H}_{\mathrm{CH}_{3}}\right) 6.77$ Gauss. The best agreement with experiment was obtained with the UDZ basis set when considering the free rotation of the methyl group. Difference between this value and the experimental one is just about $0.5 \%$. Interesting is also that the results obtained by the free rotation are more accurate relative to experiment comparing to the statistically weighted ones, which are a little underestimated.

\section{Inclusion of molecular dynamics and the explicit treatment of solvent}

Temperature profiles of MD calculation of TMPD with or without explicit solvent molecules of ACN are shown in Fig. 4a, b, respectively. The temperature profile is much more smooth in the case of the larger system (TMPD with 13 molecules of acetonitrile, abbreviated as $\mathrm{TMPD}+13$ ), see Fig. 4a. The last 0.02 ps was the temperature of the TMPD+13 system in a $20 \mathrm{~K}$ interval around the temperature of the thermostat, which is an acceptable result. Nonetheless, the temperature oscillations below $4 \mathrm{~K}$ are desirable. All geometries used in the succeeding HFCC calculations (Table 4) were gained from the time interval $0.05-0.10$ ps (last 500 and/or 250 time steps) of the MD simulations. The still present oscillations in the temperature profile might be caused by a still small number of degrees of freedom which did not allow a unique/ fair distribution of the kinetic and potential energy within the system (temperature is defined exclusively via kinetic energy). Temperature is changing much more rapidly in the case of the MD simulations of the TMPD molecule without solvent molecules and the magnitude of the oscillations of the temperature are large comparing to TMPD+13 system as well, see Fig. 4b.
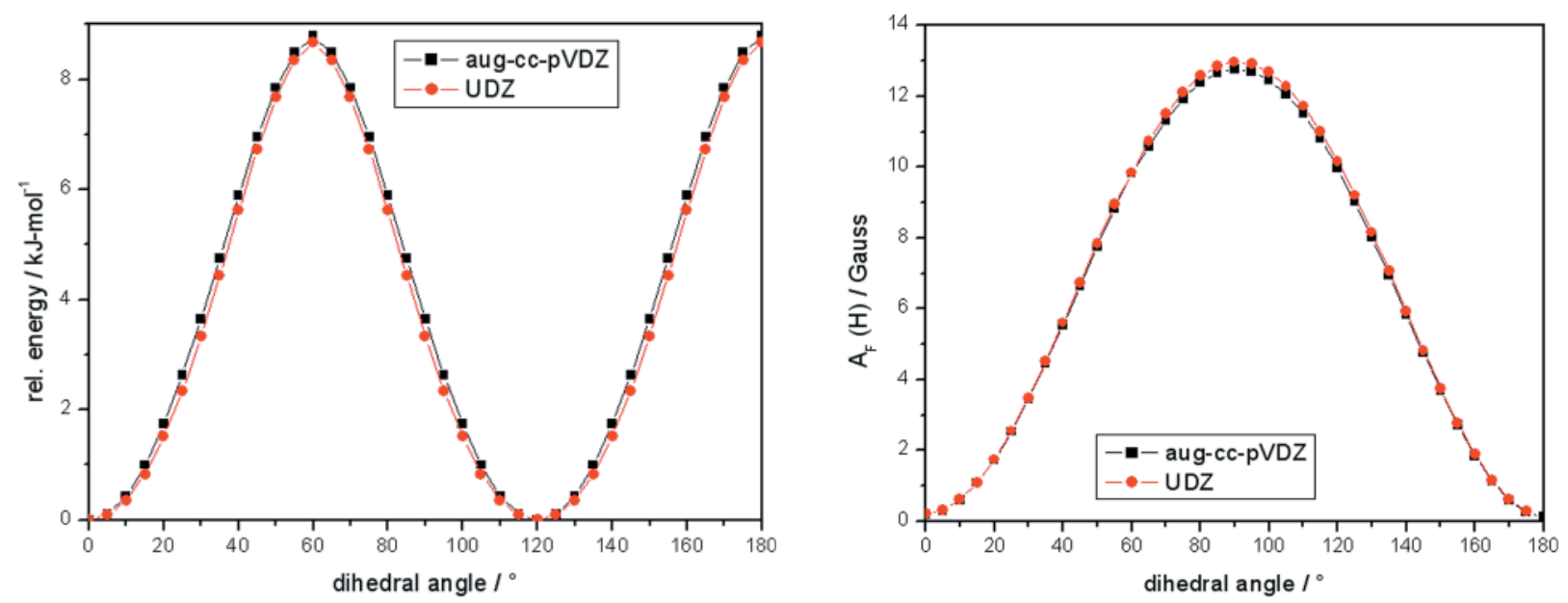

Fig. 3a, 3b. Dependence of relative energy of TMPD in $\mathrm{kJ} / \mathrm{mol}$ (a, left) and $\mathrm{A}_{\mathrm{F}}\left(\mathrm{H}_{\mathrm{CH}_{3}}\right)$ in Gauss (b, right) on the dihedral angle of methyl group rotation.

Tab. 3. B3LYP in vacuo HFCG of the rotated methyl group hydrogens.

\begin{tabular}{ccccc}
\hline Basis set & $\begin{array}{c}\text { simple arithmetic } \\
\text { mean (Tab. 2) }\end{array}$ & $\begin{array}{c}\text { conformation analysis } \\
\text { (Tab. 1) }\end{array}$ & $\begin{array}{c}\text { free rotation } \\
\text { (Fig. 3) }\end{array}$ & Boltzmann statistics \\
\hline aug-cc-pVDZ & 6.645 & 6.636 & 6.634 & 6.446 \\
UDZ & 6.701 & - & 6.739 & 6.566 \\
\hline
\end{tabular}


The lower quality of the basis set during the MD simulations was caused by the computational costs of one ab-initio step. The MD calculations (M06/321G) of the TMPD molecule (140 functions) of 1000 time steps took 68 hours of CPU time. On the other hand the M06/3-21G TMPD+13 calculation (569 functions) of 1000 time steps took 1400 hours of CPU time.

The values of the B3LYP/cc-pVDZ HFCC obtained upon the MD geometries are presented in Table 4. A very nice agreement with experiment (7.051) was obtained by means of combining the molecular dynamics for the 500 last time steps and HFCC calculations for the nitrogen atom (7.046), see Table 4. The difference with experiment is just $0.01 \%$. On the other hand, the results are not so satisfactory in the case of the methyl group hydrogens. Even a simple arithmetic mean of the fixed methyl group hydrogens (from previous calculations of conformer 4a) gives a better agreement with experiment than the MD based HFCG. The difference between the simulated and the experimental HFCCs is probably caused by the low quality of the basis set (3-21G), the short duration of MD and a still small size of the system. HFCGs of the hydrogens of the aromatic ring, which are obtained as the average of the MD geometries, are comparable with those obtained by a simple arithmetic mean of the 4 a conformer (1.712 and 1.704, respectively).

In addition, the temperature is not well behaved for the TMPD+13 system by means of the thermostat in the time span 0.05-0.075 ps. And although the results are encouraging, it seems more appropriate to account only the last 250 time steps in the calculation of HFCG, for which the temperature of the system agrees better with the thermostat. In this case the HFCCs are less satisfactory in comparison with experiment, though. The change of $A_{F}(N)$ was the largest, about $4 \%$. It is interesting because the temperature was better defined in the final time span, i.e. better than in the case of the original span (500-1000). However the $\mathrm{A}_{\mathrm{F}}(\mathrm{N})$ value is still in a better agreement with experiment than the B3LYp/ cc-pVDZ value for the 4 a conformer (see Table 2). Unfortunately, the MD simulation did not lead to an overall improvement of the agreement between the calculated and experimental HFCG values.

\section{Conclusions}

The choice of the level of theory turns out to be a key factor for accurate HFCG calculations. The results obtained at the DFT level of theory are in better agreement with experimental values comparing to UHF or MP2 calculations. Although we have chosen the B3LYP functional within this study, the remaining functionals (PBE, BLYP, M06, PBE0) are well suited for HFCG calculations as well. Besides the computational method, the choice of basis set is of non-negligible importance in HFCC calculations as well. HFCCs obtained with Pople style basis sets (like 3-21G, 6-31G or 6-31g*) are less accurate
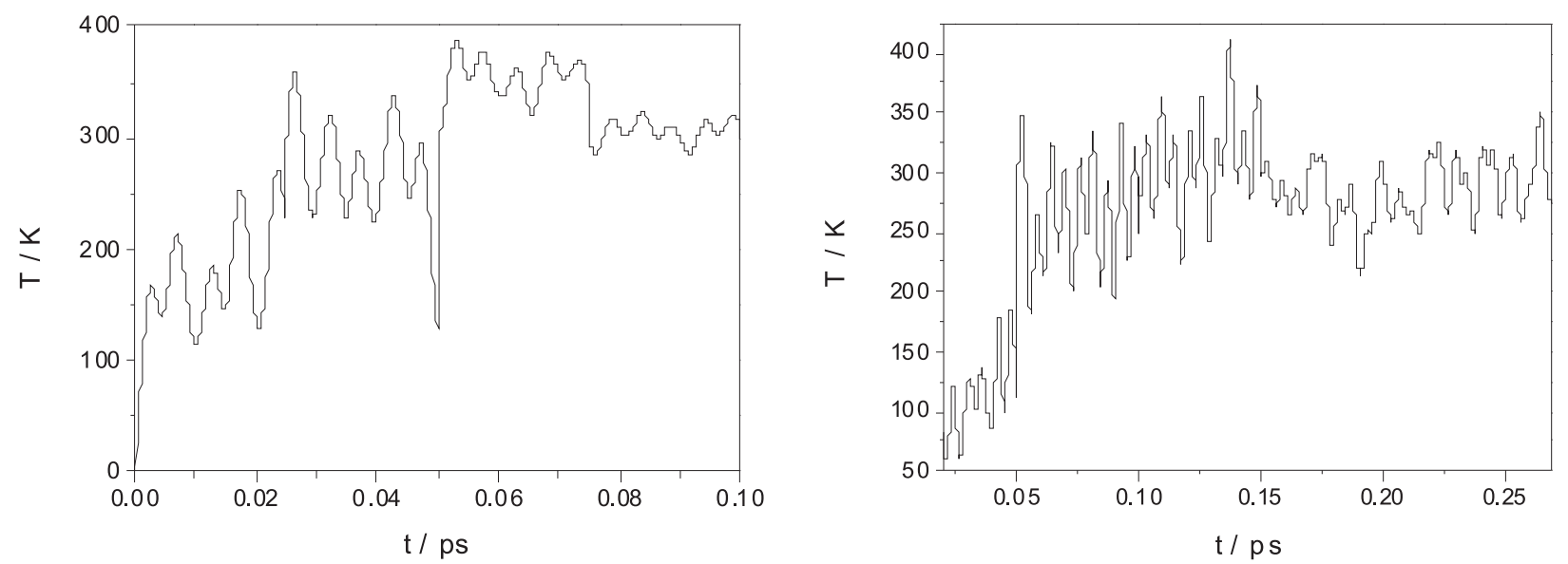

Fig. 4a, 4b. Temperature profile of MD simulations of TMPD+13 (left) and TMPD (right) (M06/3-21G basis set).

Tab. 4. Table of HFCG from MD geometries for B3LYP/ cc-pVDZ method (in Gauss).

\begin{tabular}{ccccc}
\hline time steps span & system & $\mathrm{A}_{\mathrm{F}}(\mathrm{N})$ & $\mathrm{A}_{\mathrm{F}}\left(\mathrm{H}_{\text {arom }}\right)$ & $\mathrm{A}_{\mathrm{F}}\left(\mathrm{H}_{\text {methyl }}\right)$ \\
\hline $500-1000$ & TMPD+13 & 7.046 & -1.712 & 6.291 \\
$750-1000$ & TMPD+13 & 7.318 & -1.715 & 6.168 \\
$2000-2500$ & TMPD & 6.498 & -1.626 & 6.503 \\
\hline
\end{tabular}


than the DZ family basis sets (like cc-pVDZ and augcc-pVDZ). On the other hand, the cc-pVTZ and cc-pVQZ basis sets have also worse agreement with the experimental HFCC values comparing to the cc-pVDZ / aug-cc-pVDZ and UDZ basis sets. The uncontracted UDZ basis set has been chosen in the believe that it could further improve the electron/ spin density behavior at the nucleus. Nonetheless, no serious effect of the contraction scheme on HFCC is found, i.e. the contracted basis sets are able to describe the core electron spin density properly for light elements and are found actually more accurate for the HFCC of the nitrogen atom.

The influence of the solvation model is found not very significant in the case of TMPD. The differences between the employed solvation models (PCM, CPCM) and solvents (ACN, $\mathrm{MeOH}$ ) are negligible compared to the impact of the choice of basis set or method of HFCC calculation. Nonetheless, the inclusion of the solvation models is found very important in HFCG calculations of compounds containing the $\mathrm{NO}_{2}$ group for instance (Rimarčík et al. 2011) so our result cannot be taken as a general rule.

The conformation analysis yields in the case of the TMPD molecule only one stable conformer, nonetheless the inclusion of Boltzmann statistics seems an interesting option for the HFCC calculations. Studying the issue of the equivalence of methyl group hydrogens revealed that considering the HFCC for the free rotation of the methyl group is closer to real experiment than a simple arithmetic mean of the methyl group hydrogens for the most stable conformer. The value of HFCC of the methyl group hydrogens obtained by this approach was 6.74 Gauss (the experimental one was 6.77 Gauss [exp1]). A little bit worse was the statistically scaled value for the methyl group rotation (6.57 Gauss), but it was still satisfying in comparison with experiment.

Inclusion of the solvent molecules explicitly in the MD simulation (realized by NWChem package) was introduced as well. Although a basis set of lower quality (3-21G) was used during MD and the MD duration was very limited, the computed value of HFCC of nitrogen (7.046 Gauss) is in an excellent agreement with experiment (7.051 Gauss). This result shows the great promise of this method. Unfortunately, in the case of HFCCs of hydrogens (both of aromatic and methyl group's ones) we were not so successful, yet. The mentioned low quality of the basis set, short duration of the simulations and the size of the system seem to be the most limiting factors in the presented MD simulations.

Nonetheless, molecular dynamics is a promising method for approaching similar conditions in ab-initio calculations as those found in a real experiment and we plan to focus further on this topic in the near future (like using basis sets of higher quality, using a shorter time step and/or a longer duration of MD to achieve significantly better agreement, robustness and repeatability in comparison with experiment).

\section{Acknowledgement \\ This work was supported by APVV (APVV-0202-10) and VEGA (contract No. 1/0127/09).}

\section{References}

Adamo C, Barone V (1999) J. Chem. Phys. 110: 6158.

Alder BJ, Wainwright TE (1957) J. Chem. Phys. 27: 1208.

Barone V Recent Advances in Density Functional Methods, Part I, Ed. D. P. Chong (World Scientific Publ. Co., Singapore, 1996).

Barone V, Cossi M (1998) J. Phys. Chem. A 102: 1995.

Becke AD (1988) Phys. Rev. A 38: 3098.

Binkley JS, Pople JA, Hehre WJ (1980) J. Am. Chem. Soc. 102: 939.

Bylaska EJ, de Jong WA, Govind N, Kowalski K, Straatsma TP, Valiev M, Van Dam HJJ, Wang D, Apra E, Windus TL, Hammond J, Autschbach J, Nichols P, Hirata S, Hackler MT, Zhao Y, Fan PD, Harrison RJ, Dupuis M, Smith DMA, Nieplocha J, Tipparaju V, Krishnan M, Vazquez-Mayagoitia A, Jensen L, Swart M, Wu Q, Van Voorhis T, Auer AA, Nooijen M, Crosby LD, Brown E, Cisneros G, Fann GI, Fruchtl H, Garza J, Hirao K, Kendall R, Nichols JA, Tsemekhman K, Wolinski K, Anchell J, Bernholdt D, Borowski P, Clark T, Clerc D, Dachsel H, Deegan M, Dyall K, Elwood D, Glendening E, Gutowski M, Hess A, Jaffe J, Johnson B, Ju J, Kobayashi R, Kutteh R, Lin Z, Littlefield R, Long X, Meng B, Nakajima T, Niu S, Pollack L, Rosing M, Sandrone G, Stave M, Taylor H, Thomas G, van Lenthe J, Wong A, Zhang Z, "NWChem, A Computational Chemistry Package for Parallel Computers, Version 6.0” (2010), Pacific Northwest National Laboratory, Richland, Washington 99352-0999, USA.

Dunning TH (1989) J. Chem. Phys. 90: 1007.

Fermi E (1930) Z. Phys. 60: 320.

Frisch MJ, Trucks GW, Schlegel HB, Scuseria GE, Robb MA, Cheeseman JR, Montgomery JA, Vreven Jr. T, Kudin KN, Burant JC, Millam JM, Iyengar SS, Tomasi J, Barone V, Mennucci B, Cossi M, Scalmani G, Rega N, Petersson GA, Nakatsuji H, Hada M, Ehara M, Toyota K, Fukuda R, Hasegawa J, Ishida M, Nakajima T, Honda Y, Kitao O, Nakai H, Klene M, Li X, Knox JE, Hratchian HP, Cross JB, Adamo C, Jaramillo J, Gomperts R, Stratmann RE, Yazyev O, Austin AJ, Cammi R, Pomelli C, Ochterski JW, Ayala PY, Morokuma K, Voth GA, Salvador P, Dannenberg JJ, Zakrzewski VG, Dapprich S, Daniels AD, Strain MC, Farkas O, Malick DK, Rabuck AD, Raghavachari $\mathrm{K}$, Foresman JB, Ortiz JV, Cui $Q$, Baboul AG, Clifford S, Cioslowski J, Stefanov BB, Liu G, Liashenko A, Piskorz P, Komaromi I, Martin RL, Fox 
DJ, Keith T, Al-Laham MA, Peng CY, Nanayakkara A, Challacombe M, Gill PMW, Johnson B, Chen W, Wong MW, Gonzalez C, Pople JA, Gaussian, Inc., Wallingford CT, 2004.

Grampp G, Kelterer AM, Landgraf S, Sacher M, Niethammer D, Telo JP, Dias RMB, Vieira AJSC (2005) Monatshefte fur Chemie 136: 519-536.

Hehre WJ, Ditchfield R, Pople JA (1972) J. Chem. Phys. 56: 2257.

Kim K, Jordan KD (1994) J. Phys. Chem. 98: 10089.

Krishnan R, Binkley JS, Seeger R, Pople JA (1980) J. Chem. Phys. 72: 650.

Lee C, Yang W, Parr RG (1988) Phys. Rev. B 37: 785.

Miertus S, Scrocco E, Tomasi J (1981) Chem. Phys. 55: 117.
Moller C, Plesset MS (1934) Phys. Rev . 46: 618.

Parr RG, Yang W, Density-functional theory of atoms and molecules, Oxford Univ. Press, Oxford, 1989.

Perdew JP, Burke K, Ernzerhof M (1996) Phys. Rev. Lett. 77: 3865 .

Rimarčík J, Punyain K, Lukeš V, Klein E, Dvoranová D, Kelterer AM, Milata V, Lietava J, Brezová V (2011) J. Mol. Struct. 994: 61.

Rimarčík J, Punyain K, Lukeš V, Klein E, Kelterer AM, Milata V, Brezová V (2010) ACS 3: 20

Stephens PJ, Devlin FJ, Chabalowski CF, Frisch MJ (1994) J. Phys. Chem. 98: 11623.

Zhao Y, Truhlar DG (2006) J. Chem. Phys. 125: 194101. 